HSS IV.1 (2015)

DOI: $10.1515 /$ hssr -2015-0005

\title{
A Morpho-typology of Textual Geneses
}

Angel Radu Bagdasar*

Académie de Versailles, France

\begin{abstract}
Belonging to the textual genetics, discipline that studies the creation process of major literary or scientific works, the following paper discusses the Crocian myth of the uniqueness of the work that implies the uniqueness of the genesis. The work isn't unique but just original and its genesis too. This hypothesis also allows also the articulation of common morphologies of the process of the invention. The paper proposes a plurality of types of genesis, such as the linear, canonic or partial, that aren't able to satisfy the needs of the individual project (genesis), and twin genesis or hypergenesis, of which genetic substance supersedes the needs of an individual project, nourishing other works that constitute themselves into typological families. Such a classification represents an efficient epistemological instrument to studying the genesis of various texts. This kind of view is an entirely new way of looking at the invention and creation processes.
\end{abstract}

The supposition, inspired at his time by Croce, that the writer is a "unique" person and the work a "unique" entity constitutes a major obstacle that hinders the progress of genetic studies. An extreme assertion with huge implications in the aesthetic field vision and conception. Since it became a tyrannical and devastating "truth". In our case, the logical consequence of this fact is that the general, transindividual study is meaningless because there is no component of generality in the object. Thus, an agnostic sphere is created around the individual, that prohibits any attempt at an epistemological examination

PhD, 9, av. de la Division Leclerc 92310 Sèvres, France; e-mail : radu1944@live.fr 
of the support of generality: the common language, the identifiable interior universe, ideas or parts of ideas that are known. As a practical consequence there are no studies that go beyond the genesis of the individual work of a writer. This is monadism through and through, with all its negative implications for a scientific vision on the genesis both at individual (only one work) and ofat the collective level: the way in which the multiple creations are entwined.

Both Tthe suppositions bearing on a unique author and on a unique work in the rigorous sense of the word are both erroneous. A unique object - which exists in the known universe as only one piece - could not be identified as author or work for the simple reason that we would not have the comparison element with which to do so. By definition, a unique thing we see for the first time cannot be denominated, that is associated to any category of known thing and therefore it cannot be understood either. At best, it can be described. On the other hand, the supposition of uniqueness contradicts the elementary philosophical principle that posits that any object in the universe is a synthesis of the general and the singular.

Practically, a work is made up of common words, it complies with certain aesthetic rules that identify it as poetry or prose, and uses images which are often taken from daily life. All these are general elements, in the end. Freud remarks in poets (Dichters) the tendency

|... to diminish the distance separating their particularity from the general human essence; they assure us frequently that in each man lies a poet (Dichter) and that the last poet will die only when the last man dies. (Freud 1988: 34)

The idea that the work, and the less so the writer, are unique entities cannot be supported in any way. In fact, Croce seems to have used the term "unique" as a sort of hyperbole for something extremely original, more original than the current original in daily life. Taking the term in its proper sense, his ideological descendants were thrown into an epistemological impasse. The error was totalitarian, and its consequences of late so negative that a rigorous correction should be made.

For methodological purposes we will posit the existence of an 
archwriter (archauthor), an image of the dominant behaviour of the writers and of their specific potential. The concept could also reveal the most general aspects of the literary gestation and its unexpected turns. In fact, we should conceive his behaviour in the spirit of the "multiple thinking" of Orwellian descent. We could therefore present the archwriter in a bipolar manner: on the one hand, within a synthetic $a$ priori judgment a Kant, under the incidence of the general, the characteristic, of the most frequent, of the behavioural dominant in the branch of writers, and on the other hand under the incidence of everything that destabilizes the first pole: behavioural eccentricities, rare phenomena, negations of the literary spirit, such as the logical writing of the poem The Raven by Poe or Queneau's combinatory creations. In the same contradictory concept we find therefore the writer and the antiwriter, the stable core and all the diverging recorded or virtual tendencies, the essence of the status of writer and the dialectics of the evolution along all its proper ontological axes. This procedure shelters us equally from a lack of representativeness of our subsequent construction resulting in a disproportionate slide towards the particular, and from an impending drabness, or obsolescence that could engulf us if we insisted excessively on the general element to the detriment of the centrifugal, constantly heterodox invention. The following typology concerns therefore the archwriter.

To distinguish between the most frequent operational types of architecture, or types of genesis, appears to us of primordial importance not only for concrete analyses but also for decoding the few fundamental coordinates pertaining to the creative vocation of the human being.

I. We must introduce for methodological reasons a kind of degré zéro of genesis called linear genesis, orthodox or canonical, around which all the particular, non-canonical types of geneses gravitate. We have defined linear genesis as the genesis where the asemic and the semic plans coincide. The three stages, the incipit, the plan, and the "textualization" occur integrally, each in its place in the genetic chain, and all three in their indicated canonical order. On the other hand, the heuristic substance of the incipit of a canonical genesis is neither inferior nor 
superior to the genesis of the programmed work. Its heuristic potential is 1 (one). Hérodias by Flaubert or Germinal by Zola provide a genetic mechanics that is a perfect epitome of canonical genesis.

In order to understand its functioningoperation we will examine the case of Flaubert's Hérodias that seems exemplary to us. We know only too well that Flaubert was concerned, long before he began to work properly on the project, with the idea of writing a novel based on a Biblical topic. He invested therefore a considerable amount of ad-hoc reflection in order to reach the pivotal image of Herod-Antipas leaning on the banister of his palace terrace. This image is, in fact, the signal of the crystallization and interior arrangement of an advanced form of incipit, if not of certain elements of the plan. FThe fact is that from the respective moment when Flaubert knew what he had to do and set down to work. The first notation attested bearing on the contents of the novel we could find in a letter of Flaubert to his friend Madame Roger Genettes on April 1876:

[...] je vois, (nettement, comme je vois la Seine) la surface de la mer Morte scintiller au soleil. Hérode et sa femme sont sur le balcon d'où l'on découvre les tuiles dorées du temple.

This is the first (mental) stage in the genesis of this text.

The effective work onto this project begins a few months later, on august 1876, when we can read in his drafts the following notation :

Machaerous. Fortress, city, landscape, morning.

King Antipas on the terrace [...] (Flaubert N. A. Fr. 23663, t. II)

In the final form of the novel, the part corresponding to this macroscopic requirement reads like this:

The citadel of Machaerous rose east of the Dead Sea, on a cone-shaped basalt peak. Four deep valleys surrounded it, two on the side, one in front, the fourth beyond. The houses were crammed near the base, in the circular interior of a wall undulating along the uneven ground: a zigzagging road cutting into the rock connected the city to a fortress the walls of which stood one hundred and twenty feet high, with numerous angles, battlements 
HSS, vol. IV, no. 1 (2015): 59-71

on the border, and, here and there, towers that seemed jewels of this stone crown suspended above the abyss.

Inside stood a palace adorned with porticos and topped by a terrace bound by a sycamore banister in which pillars were planted to support a velarium.

One morning, before dawn, tetrarch Herod Antipas came to lean against the banister and look $[\ldots]$

We see a quasi mechanical increase of the initial idea. It is enriched at the details level without any qualitative change. If Herodias' genesis is an orthodox one this does not mean that Flaubert, with his irrepressive drifting, is always an author of a definite canonical type from this point of view. It is Zola who rather fits into this category. In our presentation, orthodox genesis has a double image: of a type in itself, because it can be identified in the manner of work of certain authors, and then instrumental, serving to define the profile of the others.

II. We will now embark on the first type of particular, non-canonical genesis which is partial genesis, defined as a genesis coming out of a partial incipit. If we think of geneses as that of the first edition of The Apprenticeship of Wilhelm Meister, it becomes obvious that they are based on an incipit, and in general, on a partial macroscopic as related to the macroscopic that will constitute the basis of the final edition.

In order to better use the elements already at hand, I have disarticulated the whole first part and thus, melting the new into the old, I will create two parts. Now, I will have copied everything that has been printed; I mark the places where I want to intercalate something new, and when the copyist comes to such a mark, I will dictate the continuation to him. This way I am forced not to interrupt the work. (Goethe 1988: 184)

It is obvious that Goethe created something new starting from the partial foundations of something old. The first edition was a partial genesis that the interior genome of the author never acknowledged as perfectly legitimate. This explains the resumption of the work until the moment the interior genome is brought on an equal footing with the reality of the ne varietur text. 
III. The plurigenesis is an ensemble of a minimum of two geneses that have at least one procedural section in common. On the other hand, we can also meet a plurality of geneses, the body of which resents identical (Siamese) phenomena in several segments.

This type of project is symptomatic of the constant preoccupation of the authors on wide temporal ranges, possibly throughout their lifetime. Part of the activity of Pirandello, Anatole France, Julien Green, Dostoevsky, Giono, Bernanos tends to appear in the shape of a family of geneses-works, springing from a long-haul concern. Thus, the preoccupation with the gory 1789 Revolution materialized, with similar procedural elements, in Anatole France's activity on the series: Les Temples de la peur, L'Etui de nacre, Les Dieux ont soif, Le Livre de mon ami. The two Mouchette of Bernanos were also the fruit of connected interests.

In the case of any plurigenesis we distinguish an autonomous genetic part, which engenders the differences of the works in plurigenesis, conferring a particular countenance to each of them, and a common genetic part of two or several projects. The latter is responsible for the affinities between the works associated in the same plurigenetic family.

The plurigenesis may provide an answer from a genetic angle to the matter of variants to a work, in poetry or prose. Anyway, by using the Hamming structured distance ${ }^{1}$ at the level of contents and at the operational level we can establish if a text is a variant, which implies a considerable closeness to a basic text used as reference or to an independent work, the result of a plurigenesis.

IV. A sub-species of the plurigenesis, in its most restricted form, could be called the gemeled genesis. Siamese or gemeled genesis is the plurigenesis that involves two projects. Facts prompt us to perceive it as a separate category because a certain number of authors think and operate genetically in dual terms: hypothesis-counter-hypothesis, question-answer, thesis-antithesis, actual reality-commentary, etc. One of the works can be the answer, after years, the commentary, the conclusion to the problem raised by the first. In other words, a work opens up a universe of problems that the author is not ready to deal with in gnoseological terms, these problems pertain to an interest or to a hot reality that should be imperatively presented. Gide is the most well- 
known example when it comes to gemeled genesis. Le Retour de l'U.R.S.S, Retouches a mon retour de l'U.R.S.S, then the novel and the farce with the same name, Les Caves du Vatican, Les Nourritures terrestres, Les Nouvelles nourritures, Les Faux-monnayeurs, Le Journal des Faux-monnayeurs, Les Cabiers d'André Walter, and Les Poésies d'André Walter. We have mentioned before the organization at the first level of diptychs of the two organically blended volumes of Jules Romains's Les Hommes de bonne volonté.

The gemeled genesis of this type appears to us to be the epiphenomenon of a modern type of author who has abandoned absolute and uncontested truths, as well as the mantle of the omniscient and omnipotent classical author. He is torn by doubts and does not hesitate to make them public, while supplying himself with contradictory or complementary cues.

V. Much more complex than the gemeled genesis is genetic saturnism. The most characteristic example seems to us that of Pirandello. The experts in Pirandello's manuscripts are familiar with the fact that the genesis of his plays swallows the genesis of certain short stories written and published before. Jean Giono follows the same process in the case of Dragoon, engulfed by The Iris of Susa.

Most of the authors shy from such procedures, which do not mean they are not used, the justification being the new meanings and the clearly superior quality that the genesis swallowed by an ampler genesis adds to the pre-existing text.

VI. For genetic configurations such as those of Marivaux's La Vie de Marianne or Dostoevsky's The Life of a Big Sinner/The Possessed we can speak of a detoured genesis. It is the result of a fracture likely to change the evolution of things going on with a gestation. Not so important to speak of a failed genesis, but sufficiently important for the project to change direction. In terms of the conflict tearing at the author vis-à-vis the respective idea, the detoured genesis represents a secondary degree of seriousness as compared to the failed genesis. We are talking about the emergence of two genetic paradigms (possibly two incipits) sufficiently different to allow us to mention totally different geneses, at least in some cases. 
In a certain sense, detoured genesis is the opposite of gemeled genesis because the latter two geneses have a part in common (in the case of detoured genesis) a single genesis has two bodies, if we may put it like that.

VII. Technically, we can speak of authors who practice polyphonic or counterpoint genesis. In this case it is less an intrinsic property of the genesis and more a work style of the author. We should not mix up plurigenesis with polyphonic genesis. While plurigenesis can be defined as an ensemble of geneses having common operational elements, the geneses entwined by the creator have nothing in common with each other in the case of the polyphonic genesis.

The phenomenon, likely to cause wonder in the lay public, is rather the outcome of psychological laws. What is it all about? These are the facts. Robert Setrick, an expert in Voltaire, informs us that the Ferney wise man — his last tragedy still unfinished- "[...] emended it with one hand, while with the other he worked on a book about Britain." (Voltaire, 1975: 13) In June 1949, Mircea Eliade worked alternatingly on The Night of St. John and Shamanism, with excellent results in both cases, as we all know. Flaubert thought of Hérodias while still writing at $A$ Simple Heart, and the incipit of Hérodias is rooted, in point of time, in the genesis of the last of the Three Stories. Gilles Delisle observes that slanderous tongues (among whom Stendhal, too) claimed that, once George Sand had finished a novel, she would immediately start another. The same evening, after having found an adequate end to the adventures of Francois le Champi, she did not hesitate to turn out a few background pages for Little Fadette. The strange thing in these cases is that the author goes from one genesis to another in "flux tendu" (marketing term), needing no time to meditate. How was that possible?

The explanation is logical. The creator is a master of the unconscious. In fact, his or her psyche works at two levels, one independent from the other, the consciousness and the unconsciousness. While at the conscious level the writer can be fully committed to the drawing up of a work, his or her unconscious can concentrate on another project (or can, just as well, concentrate on the project under way, in which case its evolution can suffer major alterations). The transfer to the unconscious 
occurs specifically when the author meets with difficulties in carrying out a project. We can say that his or her personality is practically doubled by a conscious ego, and an unconscious alter ego. The time interference of the periods for the contents of the two levels to mature has effects like the ones described.

In general, the writing (textualization), a basically technical, artisan stage that presupposes a priori clarification of the major problem, has comfortable physical duration, liberating the unconscious from the pressure of major invention, making it available for the incubation of other project cores. Thus, most of the time, the end of the final stage of a project can be entwined to another, with no hiatus whatsoever. Balzac, Goethe, Flaubert, George Sand, Mircea Eliade, Henri Troyat, Erle Stanley Gardner left hanging the threads of two or several stories while they apparently dedicated themselves to the ongoing work, with exceptional results in the administration of the psychological time. Gardener (1889-1970) wrote three, four or even up to seven novels at the same time throughout his writing career. The genesis of Balzac's Illusions perdues spanned several periods, 1836, 1838, 1843, separated by considerable time intervals.

VIII. At the opposite pole of partial genesis, and at the same time the most spectacular form of genesis is that of hypergenesis. Defined in its relation with the hyperincipit, hypergenesis covers, in a unity of the basic idea (incipit) the creation of an ensemble of distinct projects. Obviously, the hypergeneses are genetic forms of ample opening that animate big projects such as Montaigne's Essays, Montesquieu's work grouped around L'Esprit des Lois, Balzac's Human Comedy, Galsworthy's Forsyte Saga, Jules Romains' Les Hommes de bonne volonté, and, why not, A Study of History, a ten-volume work by the last great world historian, Arnold Toynbee. They are brought together by a unique intention, and the author knows practically from the start that he has embarked upon a long-haul journey.

More insidious forms of hypergenesis can be identified in the case of projects that apparently have not much in common, but where one of them is made possible by the intellectual experience of the other. 
IX. Normally, we should not place failed genesis that is the zero work into a special category. We have decided right from the beginning that the existence of genetics as a science is justified by the value of the resulting works. So, when we have no value and also no work it seems futile to go on. On the other hand, we have defined the genesis as dynamics and not as a result, and genesis, be it failed, pertains to dynamics. We are therefore fully entitled to deem it a real category of genesis. Moreover, it seems to bear a special significance for that which could represent a pathology of invention. Sometimes, failure is more instructive than success, and anyway an author who has experienced one failure is much stronger, genetically speaking, than a virgin author, for the very fact that the former has, or is supposed to have, the experience of the failure and, in a way, is inured to it. FA failure may be fecund to the extent it serves to improve the system.

Why does an author of genius, with numberless successes behind him, produce a flop at a certain moment? For instance, Vigny's Sketches without a Future, as well as numberless other projects (we have quoted above Balzac, Flaubert, Gide, Roger Martin du Gard) stay unfinished or rather the author proves incapable of finishing them (sometimes, not very often, they arouse no more interest in the author.). Leaving aside physical reasons (the demise of the writer, and other exterior causes leading to interruption, such as the categorical order sent to Dostoevsky by his editor to make a translation for him while the writer was still working on The Possessed) failure can signify the author's inability to solve the problem of the project in aesthetic terms that suit him or by an emotional divorce from it.

The choice of a project - in fact, the act of imagining it, a kind of Freudian Darstellung but more developed and complex- does not take into account, with the big authors, the means, the functional and substantive-cultural elements necessary, implied by the carrying out of the project. If the project is situated outside the in-born, acquired potential and even of the dream in the sense of Jean Guillaumin, of the power to mobilize the unconscious to the task proposed by the project, it is very possible that it may fail. Obviously, in order to diagnose failure we need instruments that unfortunately are not there yet. Among others, a macrosyntagmatics of the geneses of an author to be a sort of résumé of 
this personality and able to tell us a priori whether he finds it difficult to carry out the project or not. Another reason for the failure may be the lack of interest of an author in a project that has become obsolete, that he comes to hate or that appears dangerous or uninteresting. In such cases the lack of commitment is rather emotional, and we cannot actually speak of a failure in the "gnoseological" sense of the word. Thomas Mann destroyed parts of the Diary covering the periods 1896-1917 and 1922-1932. Stendhal, starting in 1819, and Tolstoy, between 1865 and 1878, refrained from writing theirs. A connoisseur of Kafka's manuscripts assures us that his main works are posthumous and unfinished. The author of The Castle did not want to have anything published until he found everything to his liking. Frequently burning his projects and sketches had become almost a ritual with him. Besides what was actually saved, his friend Max Brod noted titles of works and scenes that his friend had read to him before destroying them. Racine himself is said to have crossed a powerful mystical crisis (in 1697) when he wanted to be rid of his profane tragedies. We can infer from all this that the plan of the creation proper, the "technical" part is separate from the attitudeemotion plan. When they are not totally contradictories.

In the case of the taxonomy presented we must specify that we are dealing with an open system, likely to be enriched with other types of geneses.

On the other hand, the categories described are not disjoined. The concrete individual geneses, and the types described do not have biunivocal but multivocal relations. A genesis can be at the same time partial, gemeled, and connected in time to others through polyphonic ties. For instance, Jean Giono worked on the Dragoon in two stages: the first was in the spring of 1965, and the second in 1967. The second version was interrupted for the benefit of another story: Olympus, itself abandoned for The Iris of Susa, written from June 1968 to October 1969. At that time, the 1965 project had been so much modified that its major elements, remixed and reformed, can be found in The Iris of Susa, while part of them, as Giono himself pointed out, were to make the subject of individual stories. Here we are clearly dealing with a counterpoint genesis, with genetic saturnism and plurigenesis.

We can conclude that a complex equation is instituted amid the 
mental type mental of the author (orphic or artisan), his culture, the circumstances of the genesis (external social pressures, difficulties of the project, biographical events ...) and the project itself. All of them make that a genesis takes a certain time and adopts a certain morphology to carry off successfully.

\section{References}

Anzieu, D. L'Auto-analyse de Frend et la découverte de la psychanalyse. Paris : PUF, 1975.

Bachelard, G. L'Air et les Songes. Essai sur l'imagination du mouvement. $10^{\mathrm{e}}$ réimpression. Paris : Librairie José Corti, 1990.

Delisle, G. «Henri Troyat - Que la Sainte Russie était belle avant la Révolution ». Paris Match. 7 mai 1992.

Eliade, M. Fragments d'un journal. I. Paris : Gallimard, 1974.

Freud, S. Métapsychologie. Paris : Gallimard, Coll. Folio Essais, 1988.

Garcin, J. «Visite à Julien Gracq ». L'Événement du jeudi. 380 (13 février 1992.

Genette, G. Seuils. Paris : Editions du Seuil, 1987.

Gracq, J. En lisant en écrivant. Paris : José Corti, 1986.

Hemingway, E. Paris est une fête. Paris : Gallimard, 1990.

Jean, R. «Lire/Ecrire ». La Pensée. n²15 (octobre1980).

Godard, H. «Présentation». Cabiers Giono 2. Dragoon suivi de Olympe. Paris : NRF, Gallimard.

Vigny, A. CEuvres complètes. vol. I. Poésie - Théâtre, texte présenté, établi et annoté par François Germain et André Jarry. Paris : Gallimard, Bibliothèque de la Pléiade, 1986.

Voltaire. Contes et Romans. Lausanne : Compagnie du livre français, 1975.

\footnotetext{
${ }^{1}$ The Hamming distance is an instrument to measure the structural distance separating two objects or two systems. It takes into consideration several criteria assessing the distance between the two objects on the axes of the respective criteria, and subsequently obtaining a balanced average of these values. This last-mentioned value measures the degree of relation between the two objects.
} 


\section{Biographical note}

Angel Radu Bagdasar is a PhD in Philology in 1980 at the University of Bucharest, Romania and in 2003 at the University of Artois, France. Former curator to the National Museum of Romanian Literature (1975 - 1989), and associated researcher to the National Center of Scientific Research, Paris (1990 - 1991). High School professor (1999-2012) in the aria of Academy of Versailles. Specialized in manuscriptology and textual genetics. Four published books: Informatica mirabilis. Arta si literatura de calculator (Dacia, Cluj-Napoca, 1982); Criticã și ciberneticã (Universe, Bucharest, 1983), Emil Cioran - Itinéraire d'un exilé métaphysique (ANRT, Lille, 2003), Creatica I. O Teorie a genezei operei literare (Paideia, Bucharest, 2005). 